\title{
Effects of Plyometric Training on Speed and Agility among Recreational Football Players
}

\author{
Muhammad Hazman bin Shamshuddin ${ }^{1, *}$, Hosni Hasan ${ }^{1,2}$, Mohd Syrinaz Azli ${ }^{3}$, \\ Muhamad Noor Mohamed ${ }^{4}$, Fatin Aqilah Abdul Razak ${ }^{5}$
}

\author{
${ }^{1}$ Faculty of Sports Science and Recreation, Universiti Teknologi MARA, Malaysia \\ ${ }^{2}$ Sports Engineering and Artificial Intelligence Center, Faculty of Mechanical Engineering, Universiti Teknologi MARA, Malaysia \\ ${ }^{3}$ Defense Fitness Academy, Universiti Pertahanan Nasional Malaysia, Malaysia \\ ${ }^{4}$ Faculty of Sports Science and Recreation, Universiti Teknologi MARA Negeri Sembilan, Kampus Seremban, Malaysia \\ ${ }^{5}$ Faculty of Sports Science and Recreation, Universiti Teknologi MARA Pahang, Kampus Jengka, Malaysia
}

Received June 29, 2020; Revised August 22, 2020; Accepted September 11, 2020

\section{Cite This Paper in the following Citation Styles}

(a): [1] Muhammad Hazman bin Shamshuddin, Hosni Hasan, Mohd Syrinaz Azli, Muhamad Noor Mohamed , Fatin Aqilah Abdul Razak, "Effects of Plyometric Training on Speed and Agility among Recreational Football Players," International Journal of Human Movement and Sports Sciences, Vol. 8, No. 5, pp. 174 - 180, 2020. DOI: 10.13189/saj.2020.080503.

(b): Muhammad Hazman bin Shamshuddin, Hosni Hasan, Mohd Syrinaz Azli, Muhamad Noor Mohamed, Fatin Aqilah Abdul Razak (2020). Effects of Plyometric Training on Speed and Agility among Recreational Football Players. International Journal of Human Movement and Sports Sciences, 8(5), 174 - 180. DOI: 10.13189/saj.2020.080503.

Copyright $\bigcirc 2020$ by authors, all rights reserved. Authors agree that this article remains permanently open access under the terms of the Creative Commons Attribution License 4.0 International License

\begin{abstract}
Plyometrics are exercises that involved the enhancement of muscle performance. The objective of this study is to evaluate the effects of 6-weeks plyometric training on speed and agility performance among recreational football players. This study was conducted following the pre-post test model of quasi-experimental method. Twenty-two recreational football players were chosen for this study (aged between 19 to 26 years old) and randomly assigned into control $(\mathrm{N}=11)$ and intervention group $(\mathrm{N}=11)$ for six weeks. Subjects in the control group did not undergo any plyometric training. In contrast, the intervention group performed plyometric training for six weeks. All subjects participated in two tests; 1) Sprint test of $20 \mathrm{~m}$ distance for speed performance and; 2) Agility test using Agility T-test for agility performance before (pre) and after (post) training. For the intervention group, significant improvement in the difference of sprint time before and after six weeks of training were discovered $(t=$ $3.76, p=0.001)$ when compared to the control group. The agility performance of the intervention group also showed a significant difference when compared to the control group $(t=2.53, p=0.01)$. Therefore, this will help players to improve their performance during a football match and prevent injury among recreational football players.
\end{abstract}

Keywords Plyometric, Recreational Football Players, Speed, Agility

\section{Introduction}

Football is a game that includes high speed runs at full or sub-normal speeds, high power projections, quick changes in ball direction. Sports coaches often design a training regime for sports coaching and performance research that covers a range of physiological and mechanical requirements. The training regime is, therefore, ready to use by athletes and coaches for their everyday sports activities. Many team sports (such as football, netball, martial arts and baseball) includes intermittent, dynamic and ballistic movement. This requires advanced conditions, along with high aerobic and intermittent sprinting capacity, strong muscles and strength, speed flexibility, speed and adaptability.

Plyometrics are exercises that involve the enhancement of muscle performance [1]. Most of the trainings in sports involve jumping, hopping, and skipping movements [2]. These exercises also facilitate sturdy muscle activities in 
energetic activities, during which the movement would come with a stretch of the muscle instantly by an explosive modification of the muscle [3].

Most researchers and practitioners share a common view that plyometric training is one of the approaches in every field often used for athletes, notably those with the short-shortening cycle (SSC). These training are designed to improve explosiveness and dynamic efficiency [4]. Previous studies have shown that through plyometric training, jumping and sprinting capabilities and specific trajectory activities could be improved [3]. An effective technique for boosting the running economy, joint stability and the severity of knee injuries was also found [5].

Intensive training with high-intensity interval training components consisting of stamina, strength, aerobic and anaerobic is a need in recreational football games. It can use a multifaceted training style, that simultaneously stimulates multiple fitness areas. As part of this analysis, research studies that can provide evidence-based advice on how to manage the best training environment to maintain maximum intensity and load for different groups of participants are of great interest [6].

Speed is defined as the ability to move or to cover a distance in a short time. In many sports, sprint performance is important. Therefore, the interest of successful athletes in learning basic skills in sprinting was high. In order to develop a successful and efficient sprint training strategies, a lot of training needs to be done, as young athletes need to be exceptionally performing in all of their sport's physical aspects (e.g. strength, stamina and exercise techniques).
The test requires a single maximum sprint with a reported time of over 20 metres. There will be a thorough warm-up, including the start of some practice and acceleration [7].

The ability to maintain a stable body position and change the direction quickly without loss of balance, body control or speed is described as agility [8]. Agility components were classified as balance, coordination, strength and speed. It is important for professional, recreational and "tactical" athletes who need the capacity to change sports or operate on all plane quickly. Improved agility benefits include increased body stability during quick motion, increased intramuscular control, and decreased risk of injury or re-injury. The Agility T-Test is an agility test for athletes that involve going forward, sideways and backwards [9].

Training for most sports requires completely different physical attributes to be stressed regularly, in order to maximise sports efficiency during the tournament. Short-run plyometric training, such as two sessions, had changed the stiffness of muscle-tendon each week for five years and has improved the strength, capacity, and SSC function of lower limbs in persons [10]. The output of a short-term experiment following a 6-week training plan could boost players' capacity, which should be of significant concern to coaches, practitioners and scientists. Therefore, this study aims to examine the effects of plyometric training on speed and agility among recreational football players. We hypothesised that plyometric training enhance speed and agility performance among recreational football players.

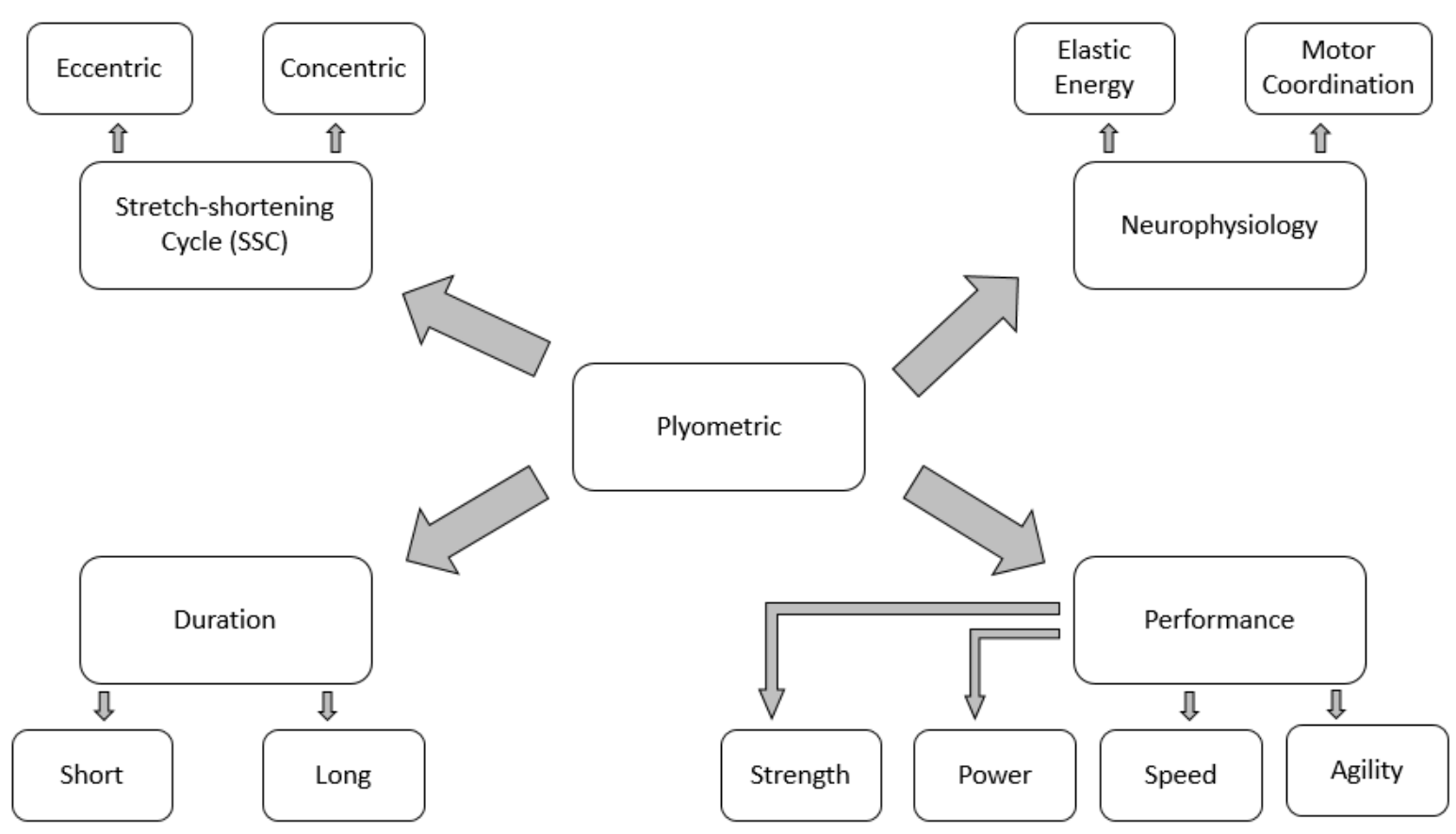

Figure 1. Theoretical Framework of Plyometric Training 


\section{Methods}

\subsection{Study Area and Duration}

This research was conducted to investigate the effect of 6 weeks plyometric training on speed and agility among recreational football players. This study was conducted following the pre-post test model of quasi-experimental method. This research was conducted for 7 weeks starting from recruitment of the participants.

\subsection{Research Design}

An experimental randomised pre-test and post-test control group design was used to test the hypothesis in this study. This design was selected because it can compare information on the subject's original condition (pre-test) with the result of post-test after they were given the training. Moreover, this design was chosen as the research was designed to see how the independent variable affects the dependent variable. The use of a control group in this study was allowed post-test result differences to be attributed to the treatment difference and no other variables.

\subsection{Participants}

The participants that participated in this study consisted of twenty-two recreational football players from Kesukeb FC with age between $19-26$ years old (age: $21.55 \pm 1.57$ years). The participants were randomly assigned into two groups; 1) control group (CG) $(\mathrm{N}=11)$ and 2) intervention group (IG) $(\mathrm{N}=11)$. This study was approved by the research ethics committee, Universiti Teknologi MARA, Shah Alam, Malaysia. The participants selected did not exhibit any presence of lower extremity injuries and did not have any medical condition. Participants were excluded if the history of injury six months ago, reconstructive lower extremity surgery in the last twelve months or musculoskeletal conditions unresolved.

\subsection{Instrument}

\subsubsection{0-meter Sprint Test}

A self-paced 3-minute warm-up run, participants performed two sub-maximum 20-meter (m) sprints from a starting line, followed by three maximum timed sprints on a flat surface football field. A 2-minutes' walk recovery interspersed each sprint. After completion, each participant's time was recorded to the nearest $0.01 \mathrm{~s}$ with a handheld stopwatch (Casio HS-3V-1R). Altmann and Ringhof [11] found the $20 \mathrm{~m}$ sprint test to be highly reliable with interclass reliability coefficient of ICCs $>0.75$.

\subsubsection{Agility T-test}

Agility t-test area was used with a scale of 10 meters by 10 meters. Participants ran forward or moved when the "go" order as quickly as possible to the central cone. Then, they ran sideway $5 \mathrm{~m}$ to the right cone and ran sideway $10 \mathrm{~m}$ away to the far-left cone to the left and ran sideway back to the middle on the right cone. The individual either ran or moved backward as soon as possible to reach the finish line. The researcher began the stopwatch (Casio HS-3V-1R) and stopped when the participant crossed the finishing line plane. The time to complete each test is measured in seconds. Pauole and Madole [12] found the Agility t-test to be highly reliable with intraclass reliability was 0.98 .

\subsection{Procedures}

Participants that fulfilled the inclusion criteria for the study were approached by the researcher to participate in this study. The participants attended a series of training sessions for plyometric two times a week for six weeks in the intervention group. The control group were free to do any activity during six weeks' time as the team did not have any training sessions, thus, it can control to minimize the Hawthorne effect among football team players. The pre-test data collected on $2^{\text {nd }}$ weeks after recruitment and post-test data collected after finish plyometric training on the $7^{\text {th }}$ weeks. The plyometric training programme was focused on frequency and volume recommended from [13]. Plyometric training sessions take about 35 minutes and start with regular 10 minutes (min) warm-up, 5 min of a jog, 5 min of stretching, and 20 min of side jumping (SJ), countermovement jump (CMJ) and double-bound leg jumping (DBJ) training and five minutes of cooling down. SJ was an exercise in which subjects had to jump side to side between a cone with feet together while CMJ needed subjects to fully bend their knees with arm swing backwards followed by one jump as high as possible with arm swing forward and upward. DBJ required the subjects to jump forward horizontally twice with both feet close together. Each exercise was performed with ten repetitions for each set. It was decided that every type of jumps were performed for four sets with ten repetitions in each set as shown in Table 1. This was because a similar intensity for six consecutive weeks may cause adaptation of neuromuscular function to the training regime. In addition, it was noted that in both low and moderate training courses a week there was an improvement in $20 \mathrm{~m}$ sprint performance, jump contact time and maximum strength compared to high training frequencies [14]. Rest was given 3 minutes between each set and 5 minutes between each exercise. 30 minutes' rest was given between testing and training. 
Table 1. Detail Description of 6th Week Plyometric Training

\begin{tabular}{|c|c|c|}
\hline Weeks & Plyometric Exercises & Repetitions and Sets \\
\hline \multirow{3}{*}{$1^{\text {st }}$ week } & Side Jump & $10 \times 4$ \\
\hline & Countermovement Jump & $10 \times 4$ \\
\hline & Double Bound Leg Jump & $10 \times 4$ \\
\hline \multirow{3}{*}{$2^{\text {nd }}$ week } & Side Jump & $10 \times 4$ \\
\hline & Countermovement Jump & $10 \times 4$ \\
\hline & Double Bound Leg Jump & $10 \times 4$ \\
\hline \multirow{3}{*}{$3^{\text {rd }}$ week } & Side Jump & $10 \times 4$ \\
\hline & Countermovement Jump & $10 \times 4$ \\
\hline & Double Bound Leg Jump & $10 \times 4$ \\
\hline \multirow{3}{*}{$4^{\text {th }}$ week } & Side Jump & $10 \times 4$ \\
\hline & Countermovement Jump & $10 \times 4$ \\
\hline & Double Bound Leg Jump & $10 \times 4$ \\
\hline \multirow{3}{*}{$5^{\text {th }}$ week } & Side Jump & $10 \times 4$ \\
\hline & Countermovement Jump & $10 \times 4$ \\
\hline & Double Bound Leg Jump & $10 \times 4$ \\
\hline \multirow{3}{*}{$6^{\text {th }}$ week } & Side Jump & $10 \times 4$ \\
\hline & Countermovement Jump & $10 \times 4$ \\
\hline & Double Bound Leg Jump & $10 \times 4$ \\
\hline
\end{tabular}

\subsection{Statistical Analysis}

In the analysis of the study, the statistic program version 25.0 of the Statistical Package for social science (SPSS) was used. To test whether data were normally distributed, a Shapiro-Wilks test was used. Both variables had a $p$-value greater than 0.05 , and parametric statistics were therefore used for analysis. For comparison of groups, data was evaluated using an independent T-test. All results were rounded to two decimals. Data with a $\mathrm{p}<0.05$ were set to be significant. Therefore, there is a significant difference in speed and agility among recreational football players who performed plyometric training and null hypothesis can be rejected. Participants were measured in kilograms $(\mathrm{kg})$ for weight, and in centimeters $(\mathrm{cm})$ for height. The sprint and agility test results were measured in seconds (s). Mean, and the standard deviation was provided as descriptive results.

\section{Results}

This research aims to investigate the effects of plyometric training on speed and agility performance among recreationally trained football players. The results of the analysis are arranged according to the following subtopics, descriptive analysis, comparison between control and intervention group, comparison the effect of plyometric training on speed between control and intervention group and comparison the effect of plyometric training on agility between control and intervention group.

Table 2 provides detailed statistics for age, height, weight, body mass indices, pre-test velocity and pre-test strength for the mean and standard deviation for the control and intervention group. The results of the independent t-tests showed that there was no statistical difference in age, height, weight, body mass, pre-test speed and pre-test agility before starting the plyometric training program $(\mathrm{p}>$ 0.05 ) between the two groups, control and intervention groups are presented in Table 3.

Table 2. Mean and Standard Deviation of Participant Characteristic, Pre-test Speed and Pre-test Agility for Control and Intervention Group

\begin{tabular}{|c|c|c|}
\hline \multirow{2}{*}{ Category $(\mathrm{N}=22)$} & $\begin{array}{c}\text { Control Group } \\
(\mathrm{N}=11)\end{array}$ & $\begin{array}{c}\text { Intervention Group } \\
(\mathrm{N}=11)\end{array}$ \\
\cline { 2 - 3 } & $M \pm S D$ & $M \pm S D$ \\
\hline Age & $21.55 \pm 1.57$ & $20.91 \pm 1.64$ \\
\hline Height & $173.8 \pm 4.72$ & $169.7 \pm 4.94$ \\
\hline Weight & $70.3 \pm 13.94$ & $64.30 \pm 9.98$ \\
\hline Body Mass Index & $23.20 \pm 4.07$ & $22.27 \pm 2.94$ \\
\hline Pre-test Speed & $3.99 \pm 0.31$ & $3.85 \pm 0.09$ \\
\hline Pre-test Agility & $13.02 \pm 0.35$ & $12.74 \pm 0.44$ \\
\hline
\end{tabular}

Table 3. Pre-test Speed and Pre-test Agility Data for Control and Intervention Groups

\begin{tabular}{|c|c|c|c|}
\hline & $\mathrm{t}$ & $\mathrm{df}$ & $\mathrm{p}$ \\
\hline Pre-test Speed & 1.41 & 20.0 & 0.17 \\
\hline Pre-test Agility & 1.66 & 20.0 & 0.11 \\
\hline
\end{tabular}

The results analyzed by Paired T-test on effect of plyometric training on speed performance show an overall significant decrease $(p<.001)$ of $6.12 \%$ after plyometric training. Table 4 shows that the comparison was statistically significant decrease in speed performance time from pre-test $(M=3.92, S D=0.24)$ to post-test $(M=3.68$, $S D=0.86$ ). The mean decrease in speed performance time was 0.24 with $95 \%$ interval ranging from 0.107 to 0.374 . There is a significant difference in the effect of plyometric training on speed between control and intervention group as the value for this comparison was found to be smaller than the significant level $(p=0.001<0.05)$ as shown in Table 5. Result showed that the intervention group had faster time during the $20 \mathrm{~m}$ sprint test after plyometric training compared to the control group. Therefore, there is a significant difference in speed among recreational football players who performed plyometric training.

The results analyzed by Paired T-test on effect of plyometric training on agility performance show an overall significant decrease $(p<.01)$ of $2.32 \%$ after plyometric training. Table 4 shows the paired t-test shows that the comparison was statistically significant decrease in agility performance time from pre-test $(M=12.88, S D=0.08)$ to post-test $(M=12.58, S D=0.12)$. The mean decrease in agility performance time was 0.30 with $95 \%$ interval ranging from 0.054 to 0.551 . There is a significant 
difference in the effect of plyometric training on agility between the control and intervention group as the value for this comparison was found to be smaller than the significant level $(p=0.01<0.05)$ as shown in Table 5. Result showed that the intervention group had faster time during the agility t-test after plyometric training compared to the control group. Therefore, there is a significant difference in agility among recreational football players who performed plyometric training.

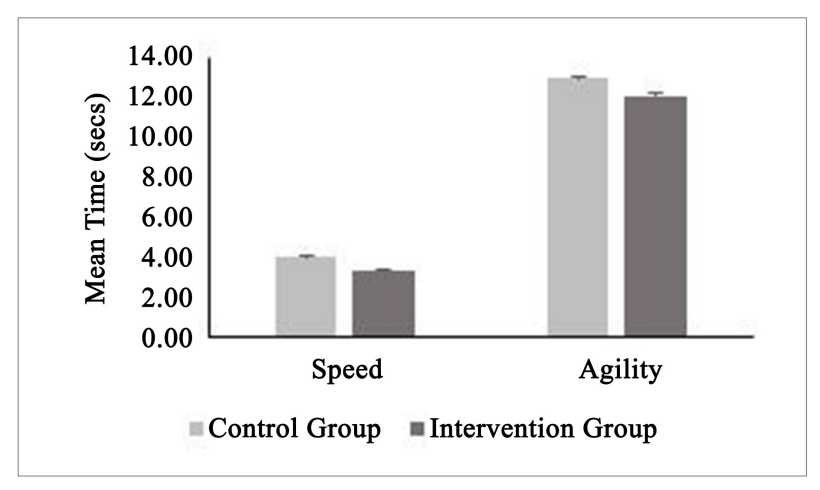

Figure 2. Post-test Mean and Standard Deviation of Speed and Agility Performance between Control and Intervention Groups

Table 4. Effect of Plyometric Training on Speed and Agility of Recreational Football Players

\begin{tabular}{|c|c|c|c|}
\hline \multicolumn{2}{|c|}{} & Mean & Std. Deviation \\
\hline \multirow{2}{*}{ Speed } & Pre-test & 3.92 & 0.24 \\
\cline { 2 - 4 } & Post-test & 3.68 & 0.86 \\
\hline \multirow{2}{*}{ Agility } & Pre-test & 12.88 & 0.08 \\
\cline { 2 - 4 } & Post-test & 12.58 & 0.12 \\
\hline
\end{tabular}

Table 5. Paired T-test for Speed and Agility Score in Pre and Post Training

\begin{tabular}{|c|c|c|c|c|c|}
\hline & & & & \multicolumn{2}{|c|}{$\begin{array}{c}95 \% \text { Confidence } \\
\text { Interval }\end{array}$} \\
\hline & Mean & $t$ & $p$ & Lower & Upper \\
\hline Speed & 0.24 & 3.76 & 0.001 & 0.107 & 0.378 \\
\hline Agility & 0.30 & 2.53 & 0.01 & 0.054 & 0.551 \\
\hline
\end{tabular}

\section{Discussion}

One of the aims of this research was to determine whether or not the plyometric training will improve speed performance. The findings show that the sprint performance of the intervention group has substantially increased after six weeks of plyometric training $(p=0.001$, $p<0.05)$. Similar results were found in previous work carried out by [15] to determine the effect of a sprint-specific plyometric intervention system on sprint-training intervention. The plyometric group showed substantial decreases in time over the sprint results at a distance of $10-\mathrm{m}$ and $40-\mathrm{m}(p=0.001)$.

Other studies have also shown that plyometric training with a distance of $30 \mathrm{~m}$ and $40 \mathrm{~m}$ respectively, as reported in [16] and [17], influenced the sprinting abilities. During the plyometric training, the stretch-shortening cycles are related to the improvement of the sprint results. This study's results illustrate the importance of achieving high strength rates to boost sprint efficiency in recreational football players, with intervention group players showing the highest sprint efficiency and control group players showing the lowest sprint performance. Importantly, plyometric training has also been shown to reduce the frequency of football players' injuries.

The current research has also consistently demonstrated that a variant plyometric frequency training (420 DJs, 840 DJs and 1680 DJs) could substantially reduce the sprinting output over time, as noted in a meta-analysed by [18]. The combination of these factors would lead to higher gains relative to the effects of each exercise alone. Furthermore, a combination of plyometric exercises (i.e., SJ + DBJ, DBJ $+\mathrm{CMJ}$ ) led to better training outcomes compared to the use of one form of exercise. Further gains in sprint performance can be caused by training consistency. Sprint times can be increased by exercising with more horizontal acceleration (e.g., bounding and running).

The ability to perform full running on short distances is considered an important part of running during football matches. Leading to better neuromuscular changes (e.g. intra and inter muscular coordination), and quick movement (based on a short stretch cycle) increases their speed of sprinting

The increase in sprint time among recreational footballers after six weeks of plyometric training is most likely due to improvement of the drive control and stretch-shortening capacity or musculoskeletal rigidity because of improved leg explosive strength [19]. Plyometric training improves the performance of the sprint, especially from $10 \mathrm{~m}$ to $40 \mathrm{~m}$ [20]. It can also refer to sprint performances, which explain the differences. As a result, plyometric training has significantly improved the performance of football players in the current study.

The results of this research showed that six weeks of plyometric training would improve the agility of recreational football players. Results of the analysis showed that plyometric training substantially increased agility and did not alter the agility of the control group substantially. The findings of this study have also substantially increased the resilience of the intervention group $(\mathrm{p}<0.05)$.

The present research has shown that plyometric preparation affects T-test agility and reduces time. Fewer research has investigated the effect of plyometric exercise on individual endurance, but the results are more robust than those from sprint tests. Thomas, French [21] found that while the sprint remained unchanged, the agility of the semi-professional adolescent footballers significantly improved for six weeks of plyometric training (9 percent). Miller, Herniman [22] showed an improvement by 5 per 
cent and 3 percent after six weeks of plyometric training, T-agility and Illinois agility test respectively. Such results are higher than those observed in other studies. However, comparisons are difficult to be made because [22] do not address the training status of the participants. Upon plyometric preparation, neural adaptation tends to be the beneficial effects of agility, primarily to enhance inter muscle coordination.

In a previous study by [2] on the efficacy of plyometric exercises for speed, jumping and agility in players, agility on both the right and left sides improved substantially after training relative to pre-training. The findings of this analysis are consistent with previous work that records similar agility improvements. In football, simple movement patterns require high agility.

After six weeks of high-intensity plyometric training (4-meter by 9-meter shuttle sprint, t-test, and agility review Illinois), study by [23] showed a major increase in the agility of young men's basketball players. A plyometric Agility T-test by [22] was used to assess agility when vertical, lateral, and horizontal plyometric jumps were used by [22] and improve agility was suggested. Miller, Herniman [22] also found that the agility of an athlete could also be improved by six weeks of plyometric training (T-test and Illinois strength test). In the same test but different study, [25] demonstrated the advantages of a short-term plyometric agility training program for young basketball players (T-testing and Illinois agility testing), demonstrating the need for plyometric training to enhance efficiency in activities requiring acceleration, decelerations and a change of course. It is also well known that agility requires generating muscle factors (such as strength and power) to increase the speed of directive change and agility seems to have a connection between energy and power [26]. Improved power output can be one of the key variables to increased agility. Therefore, in football players, both plyometric training programs can be used as an important form of preparation to preserve or enhance strength during the season.

\section{Conclusions}

All exercises and methods of outcomes used in this study had been adapted from the previous study and had been proved of its reliability and validity for research purposed. Plyometric training was carried out at the same time for every week for the subjects as the subjects were homogenous in terms of the academic schedule. Thus, removing bias through training time or regimes.

The implication to the practical practices, plyometric training method must be appropriately incorporated into an intensive training program that enhances the essential technical skills that are necessary for achieving adequate speed and agility performance among players in recreational football to develop training adaptations. The finding of this study shows an improvement of $6.12 \%$ for speed performance and $2.32 \%$ for agility performance after 6 weeks of plyometric training on recreational football player. Coaches and physical trainers can plan 6 weeks with twice a week training session as in this study protocol. These results will benefit coaches and physical trainers in the search to refine regular training routines and develop players' speed and agility performance before any game or football game.

A generalisation of recreational football players should be made to improve the accuracy of the recreational football players' representation. Thus, include more volunteers who may result in a better sample and possibly a significant difference in speed and agility between the intervention group and the control group. Different sports code such as hockey, rugby, basketball etc. recommended for future study because different sports have different type sport specific drills and different physical demands in each sport. In future study, it is recommended to use timing gate because of the accuracy of start and stop of timing. Timing gate also can be set at $10 \mathrm{~m}$ mark, and $20 \mathrm{~m}$ mark to investigate the acceleration and deceleration phase during $20 \mathrm{~m}$ sprint test. Other components such as flexibility and explosiveness also can be investigated in future research. Flexibility and explosiveness are also important components in sports movements to enhance players performance. Furthermore, observations are also needed with differing intensities and volumes of plyometric training to determine their optimum dosage for this form of preparation.

This research indicates that plyometric training is an essential component of the recreationally trained football players' training program based on results that support the theoretical principles for using these forms of training to increase speed and agility performance. Therefore, this will help players to improve their performance during a football match and prevent injury among recreational football players.

\section{Acknowledgement}

The authors are grateful to the players of football team for their participation and cooperation in this study.

\section{Ethical Approval}

The study was approved and conducted by following the ICH Good Clinical Practice Guidelines, Malaysia Good Clinical Practice Guidelines and the Declaration of Helsinki set by the board of ethics committee Universiti Teknologi MARA. 


\section{REFERENCES}

[1] Ozbar N, Ates S, Agopyan A. The Effect of 8-Week Plyometric Training on Leg Power, Jump and Sprint Performance in Female Soccer Players. The Journal of Strength \& Conditioning Research, 28(10):2888-94, 2014.

[2] Manouras N, Papanikolaou Z, Karatrantou K, Kouvarakis P, Gerodimos V. The efficacy of vertical vs. horizontal plyometric training on speed, jumping performance and agility in soccer players. International Journal of Sports Science \& Coaching, 11(5):702-9, 2016.

[3] Köklü Y, Alemdaroğlu U, Özkan A, Koz M, Ersöz G. The relationship between sprint ability, agility and vertical jump performance in young soccer players. Science \& Sports, 30(1):e1-e5, 2015.

[4] Andrade DC, Beltran AR, Labarca-Valenzuela C, Manzo-Botarelli O, Trujillo E, Otero-Farias P, et al. Effects of Plyometric Training on Explosive and Endurance Performance at Sea Level and at High Altitude. Frontier Physiology, 9:1415, 2018.

[5] Milanović Z, Sporiš G, Trajković N, Sekulić D, James N, Vučković G. Does Saq Training Improve The Speed And Flexibility Of Young Soccer Players? A randomized controlled trial. Human Movement Science, 38:197-208, 2014.

[6] Pantelić S, Rađa A, Erceg M, Milanović Z, Trajković N, Stojanović E, et al. Relative pitch area plays an important role in movement pattern and intensity in recreational male football. Biol Sport, 36(2):119-24, 2019.

[7] Tottori N, Fujita S. Effects of Plyometric Training on Sprint Running Performance in Boys Aged 9-12 Years. Sports (Basel), 7(10):219, 2019.

[8] Alricsson M, Harms-Ringdahl K, Werner S. Reliability of sports related functional tests with emphasis on speed and agility in young athletes. Scandinavian journal of medicine \& science in sports, 11(4):229-32, 2001.

[9] Raya MA, Gailey RS, Gaunaurd IA, Jayne DM, Campbell SM, Gagne E, et al. Comparison of three agility tests with male servicemembers: Edgren Side Step Test, T-Test, and Illinois Agility Test. Journal of rehabilitation research and development, 50(7):951-60, 2013.

[10] Mazurek K, Zmijewski P, Makaruk H, Mroz A, Czajkowska A, Witek K, et al. Effects of Short-Term Plyometric Training on Physical Performance in Male Handball Players. Journal of Huma Kinetics, 63:137-48, 2018.

[11] Altmann S, Ringhof S, Neumann R, Woll A, Rumpf MC. Validity and reliability of speed tests used in soccer: A systematic review. PLoS One, 14(8):e0220982-e, 2019.

[12] Pauole K, Madole KD, Garhammer J, Lacourse MG, Rozenek R. Reliability and Validity of the $t$ Test as a Measure of Agility, Leg Power, and Leg Speed in Colleg... Aged Men and Women. Journal of Strength and Conditioning Research, 14:44S 450, 2000.
[13] Markovic G, Mikulic P. Neuro-musculoskeletal and performance adaptations to lower-extremity plyometric training. Sports medicine, 40(10):859-95, 2010.

[14] de Villarreal ESS, González-Badillo JJ, Izquierdo M. Low and moderate plyometric training frequency produces greater jumping and sprinting gains compared with high frequency. The Journal of Strength \& Conditioning Research, 22(3):715-25, 2008.

[15] Rimmer E, Sleivert G. Effects of a Plyometrics Intervention Program on Sprint Performance, 2000.

[16] Comfort P, Stewart A, Bloom L, Clarkson B. Relationships between strength, sprint, and jump performance in well-trained youth soccer players. The Journal of Strength \& Conditioning Research, 28(1):173-7, 2014.

[17] Hennessy L, Kilty J. Relationship of the stretch-shortening cycle to sprint performance in trained female athletes. Journal of Strength and Conditioning Research, 15(3):326-31, 2001.

[18] de Villarreal ES, Requena B, Cronin JB. The effects of plyometric training on sprint performance: A meta-analysis. The Journal of Strength \& Conditioning Research, 26(2):575-84, 2012.

[19] Dello Iacono A, Ardigo LP, Meckel Y, Padulo J. Effect of Small-Sided Games and Repeated Shuffle Sprint Training on Physical Performance in Elite Handball Players. The Journal of Strength \& Conditioning Research, 30(3):830-40, 2016.

[20] Asadi A, Ramirez-Campillo R, Arazi H, Sáez de Villarreal E. The effects of maturation on jumping ability and sprint adaptations to plyometric training in youth soccer players. Journal of sports sciences, 36(21):2405-11, 2018.

[21] Thomas K, French D, Hayes PR. The effect of two plyometric training techniques on muscular power and agility in youth soccer players. The Journal of Strength \& Conditioning Research, 23(1):332-5, 2009.

[22] Miller MG, Herniman JJ, Ricard MD, Cheatham CC, Michael TJ. The effects of a 6-week plyometric training program on agility. Journal of Sport Science and Medicine, 5(3):459-65, 2006.

[23] Asadi A. Effects of six weeks depth jump and countermovement jump training on agility performance. Sport Science, 5(1):67-70, 2012.

[24] Robinson BM, Owens B. Five-week program to increase agility, speed, and power in the preparation phase of a yearly training plan. Strength \& Conditioning Journal, 26(5):30-5, 2004.

[25] Bal BS, Kaur PJ, Singh D. Effects of a short term plyometric training program of agility in young basketball players. Brazilian Journal of Biomotricity, 5(4):271-8, 2011.

[26] Sheppard JM, Young WB. Agility literature review: Classifications, training and testing. Journal of sports sciences, 24(9):919-32, 2006. 